\title{
John Pollock, Externalismo Epistêmico, e A NATURALIZAÇão DA JUSTIFICAÇão
}

\author{
ARTHur Viana Lopes
}

\begin{abstract}
In this paper we deal with John Pollock's criticism against externalism - the idea that a proper naturalistic theory of justification has to be internalist. We analyze whether his refutation really affects every form of externalism, particularly, process reliabilism. We present Pollock's procedural theory of epistemic norms, and discuss if his arguments are effective agains process reliabilism. We claim that the reasons presented do not really put Pollock's project in advantage.
\end{abstract}

Keywords: Epistemic externalism; naturalism; reliabilism; justification.

A literatura epistemológica disponibiliza uma variedade de abordagens distintas para o desenvolvimento de uma teoria de justificação epistêmica. Teorias já foram propostas em termos de "posse de evidência", "boas razões", "deveres epistêmicos", "bases reflexivamente acessíveis", "processos cognitivos confiáveis", etc. Diante desta variedade de interpretações, uma motivação de ordem superior tem sido determinante para muitos filósofos decidirem que tipo de abordagem deve ser favorecido. Especificamente, filósofos com tendências naturalistas favorecem teorias que podem ser naturalisticamente aceitáveis. Alvin Goldman (1979) influentemente estabeleceu um critério fundamental que deve ser respeitado por qualquer teoria de justificação para que ela possa ser realmente substantiva, i.e., teoricamente sistemática e esclarecedora: uma teoria só pode especificar quando uma crença é ou não justificada através de termos não-epistêmicos, ou seja, termos não-avaliativos. Uma vez que "justificação" por si mesmo é um termo avaliativo, uma definição de justificação que utilize outras noções avaliativas é pouco elucidativa. Para que uma teoria seja substantiva ela deve ser formulada em termos de propriedades e objetos que sejam cientificamente aceitáveis, e.g., estados de coisas, estados mentais, atitudes psicológicas, "ser verdadeiro", "causar", "ser necessário que", "implicar", etc. Satisfazer este critério foi uma prioridade no desenvolvimento da teoria de justificação de Goldman (1979, 1986), o confiabilismo de processo.

A repercussão do projeto de Goldman e de suas críticas a outras posições não apenas associou o confiabilismo ao naturalismo, mas também, de um modo mais geral, teorias externalistas da justificação ao naturalismo. Obviamente, entretanto, o naturalismo não implica o externalismo epistêmico. Certamente algumas teorias

Principia 17(1): 19-38 (2013).

Published by NEL — Epistemology and Logic Research Group, Federal University of Santa Catarina (UFSC), Brazil. 
internalistas, como abordagens deontológicas de justificação, realmente não podem gerar teorias naturalistas na medida em que sua proposta é essencialmente tentar definir justificação em termos normativos, e.g., em termos de "obrigações epistêmicas", ou seja, através de outros termos avaliativos. Outras variações do internalismo, entretanto, podem ser consideradas mais promissoras naturalisticamente dependendo da maneira como definam os fatores de justificação. O mentalismo (Conee \& Feldman 2001), por exemplo, defende basicamente que justificação é função apenas de estados mentais do sujeito cognitivo, e pode gerar uma teoria substantiva caso consiga definir justificação exclusivamente em termos de "estados mentais", "atitudes psicológicas", e outras relações e propriedades não-epistêmicas como "causar", "ser dedutível", "ser provável" (em um sentido de frequência ou propensidade) - até então, o mentalismo não foi defendido desta forma. De qualquer maneira, o confiabilismo de processo parece ser a teoria naturalista de justificação mais discutida na literatura.

Outro fator responsável pela repercussão do confiabilismo é a relação que ele estabelece entre justificação e crença verdadeira. Consensualmente a justificação epistêmica tem sido tratada em estreita relação com o conceito de conhecimento. Por essa razão, uma teoria que define justificação de um modo que a relaciona diretamente com a produção de crenças verdadeiras a torna especialmente atrativa para filósofos interessados em tópicos epistemológicos tradicionais sobre a posse de conhecimento. John Pollock (1986; Pollock \& Cruz 2004), entretanto, traz problemas para estes dois grandes atrativos do confiabilismo de processo. Pollock não só argumenta que os aspectos teóricos atrativos do externalismo são ilusórios (Pollock \& Cruz 2004), mas também que o projeto naturalista do confiabilismo é problemático, e propõe alternativamente uma teoria de justificação internalista e perfeitamente naturalista (Pollock 1986). Neste artigo nós vamos lidar com a crítica de Pollock ao externalismo de um modo geral, e analisar, em particular, o quanto ela é efetiva contra o confiabilismo de processo.

Nós vamos proceder da seguinte forma. Nas duas primeiras seções, nós vamos apresentar em linhas gerais em que consiste a teoria naturalista que Pollock (1986) defende e sua suposta refutação ao externalismo de justificação. Na terceira seção, nós vamos analisar se a crítica de Pollock (1986) realmente é eficaz contra o externalismo epistêmico. Vamos discutir, particularmente, se ela atinge o confiabilismo de processo da maneira em que é defendido por Goldman $(1979,1986)$. Nós defendemos que a crítica de Pollock (1986) não atinge realmente o confiabilismo de processo e analisamos os argumentos que Pollock e Joseph Cruz (Pollock \& Cruz 2004) apresentam posteriormente. Nós então argumentamos que parte do ataque de Pollock \& Cruz (2004) ineficazmente se sustenta em uma discordância fundamental com relação ao confiabilismo de processo sobre qual deve ser o objeto de análise de uma teoria de naturalização da justificação epistêmica, e apresentamos uma analogia que 
explicita a diferença de proposta dos dois projetos. Na quarta seção, nós analisamos que razões podem ser realmente utilizadas na tentativa de rejeição do projeto confiabilista e adoção do projeto naturalista de Pollock, e defendemos que a principal delas é o conhecido problema da generalidade. Na quinta seção, por fim, nós argumentamos que o problema da generalidade não configura nenhuma vantagem ao projeto de Pollock sobre o confiabilismo.

\section{A Teoria Procedimental de Normas Epistêmicas}

Em Contemporary theories of knowledge (1986), John Pollock apresenta uma refutação não só ao confiabilismo, mas ao externalismo como um todo. Assumindo uma concepção normativa de justificação epistêmica, ${ }^{1}$ Pollock defende o que ele chama de "a concepção de justificação como guia ou regulação para ação (reason-guiding)". Sua crítica ao externalismo se baseia essencialmente na tese de que (i) nosso raciocínio e formação de crenças são guiados "de uma forma direta" por normas epistêmicas.

Pollock defende uma tese psicológica realista sobre normas epistêmicas através de um modelo procedimental (procedural) de normas. Para ilustrar sua ideia, ele sugere que façamos uma analogia com o caso de alguém que está aprendendo a andar de bicicleta. Comumente, quando alguém anda ou tentar andar de bicicleta pela primeira vez, dizemos a esta pessoa regras como "gire o guidão para a direita para dobrar à direita" e "gire o guidão suavemente quando estiver em velocidade". Quando alguém aprende de fato como andar de bicicleta, ela ainda anda de bicicleta de acordo com as normas que aprendeu, no exato momento em que está utilizando sua habilidade, mas não precisa mais pensar explicitamente sobre elas. Similarmente, a tese de Pollock é que normas podem governar nosso raciocínio e processos formadores de crença sem que tenhamos de pensar sobre elas.

Uma rústica descrição psicológica do funcionamento procedimental de normas é a seguinte: aprender a fazer $X$ é gerar um "plano" para fazer $X$, e uma vez que isto ocorre nosso comportamento é canalizado para este plano de maneira automática, como o que ocorre com hábitos condicionados, por exemplo. Normas, propriamente ditas, são inseridas neste modelo em um papel descritivo, isto é, como parte do vocabulário que utilizamos na descrição dos "planos" que internalizamos e automatizamos para procedimentos como dirigir carros e jogar golfe. Tomando emprestada a distinção entre competência e desempenho da linguística, normas descrevem um tipo de know-how, o que nós devemos fazer para realizar o que pretendemos. Por exemplo, pensemos novamente na analogia da bicicleta: $S$ possui a competência de andar de bicicleta, as normas relativas a esta competência guiam suas ações para ser bem sucedido, e sua performance depende do quão bem $S$ se guiou por suas normas. O mesmo se aplicaria às normas epistêmicas: "minha proposta é que normas epis- 
têmicas sejam entendidas em termos de conhecimento procedimental envolvendo regras internalizadas para o raciocínio" (Pollock 1986, p.132).

A principal inspiração para a teoria procedimental são modelos de sistemas de produção em inteligência artificial. A ideia basicamente é a de que normas epistêmicas são como o banco de dados de regras que regulam a produção de informação e autorizam as inferências, deduções, induções, etc., do sistema artificial. A pretensão, é claro, não é apenas construir uma analogia, mas propor algo que é plenamente aceitável do ponto de vista naturalista, i.e., que isto é exatamente o que ocorre no nosso sistema cognitivo. Mais especificamente, a sugestão é que o "homem é um tipo de processador biológico de informação. Uma luz considerável pode ser lançada na epistemologia humana pela reflexão sobre o funcionamento de máquinas cognitivas no geral" (1986, p.149). Modelos computacionais são relevantes de um ponto de vista naturalista porque podem refletir muito do que realmente ocorre em nossos sistemas cognitivos, e Pollock, de fato, dedicou boa parte de sua carreira ao desenvolvimento e discussão de modelos formais que elucidem nosso funcionamento cognitivo (Pollock 1990, 1995, 1997, 2002, 2007; Pollock \& Oved 2006). Mas qual a relação deste projeto naturalista com o desenvolvimento de uma teoria de justificação? Pollock diz:

Para mim, a objeção mais séria [...] a todas as teorias epistemológicas existentes é de que elas são radicalmente incompletas. Embora elas possam dar descrições corretas de algumas de nossas normas epistêmicas, elas não fornecem nenhuma abordagem sistemática da justificação epistêmica. Elas não nos dizem em que justificação epistêmica consiste e não explicam por que nós possuímos as normas que nos temos. Esta objeção pode ser agora respondida. Justificação epistêmica consiste em manter crenças em conformidade [em um sentido regulativo] com normas epistêmicas corretas. (Pollock 1986, p.168, grifo nosso).

A ideia fundamental de Pollock é ontologicamente muito simples. Normas de algo são normas de como fazer algo, e isto é tudo. Nós raciocinamos porque sabemos como raciocinar. Nós temos as normas que temos simplesmente porque estas são as normas que regem nossa cognição. A teoria regulativa de justificação, desta forma, aparentemente satisfaz o critério necessário para que uma teoria seja substantiva, ou seja, ela especifica todas as condições para que uma crença seja justificada. Se admitirmos o naturalismo ontológico e a concepção cientificamente aceita de máquina cognitiva, "é uma verdade necessária que nossas normas epistêmicas atuais são corretas" (Pollock 1986, p.168). A consequência disto é um critério geral que resume a teoria de justificação epistêmica de Pollock:

Teoria procedimental de normas: A crença de $S$ em $p$ é epistemicamente justificada se e somente se $S$ é mantida ou gerada em conformidade com suas normas epistêmicas regulativas.

Principia 17(1): 19-38 (2013). 


\section{A Refutação do Externalismo}

Pollock caracteriza o externalismo como a posição de que a justificação de uma crença é, ao menos em parte, uma função de considerações externas - entendidas em termos gerais como considerações sobre fatores externos ao agente epistêmico. Dada sua concepção normativa de justificação ele então distingue duas formas possíveis de externalismo: O externalismo de crença (belief externalism) defende que as normas epistêmicas devem ser formuladas em termos externalistas. Um externalista deste tipo poderia defender, por exemplo, a norma "uma crença é epistemicamente permitida se e somente se o que é acreditado é suficientemente provável", ou a norma confiabilista "é permissível manter uma crença se e somente se ela é gerada por um processo cognitivo confiável". O externalismo de norma (norm externalism) por sua vez admite que normas epistêmicas devam ser internas, mas defende a necessidade de considerações externas na escolha de normas corretas. A teoria procedimental é uma teoria internalista porque defende que a justificação epistêmica é exclusivamente uma função dos estados internos do sujeito, neste caso, da conformidade de uma crença com as normas epistêmicas de seu sistema cognitivo. Segundo Pollock, a adoção de uma teoria regulativa implica na refutação de qualquer forma de externalismo sobre justificação. A principal razão para isto é o fato de que para normas regularem o raciocínio da maneira que ele sugere, deve haver acessibilidade direta entre as normas e os conteúdos que estas processam. "O sentido em que eles são diretamente acessíveis é o de que o acesso a eles não requerem que nos primeiro tenhamos crenças sobre eles" (1986, p.134, grifo nosso).

Contra o externalismo de crença, o argumento de Pollock simplesmente é o de que normas deste tipo não podem ser internalizadas ou acessadas diretamente e que, portanto, não podem guiar nosso raciocínio. Nós não temos acesso direto a uma norma externalista como "quando a bicicleta estiver inclinada para a direita, incline o corpo para esquerda", mas apenas a normas do tipo "quando tiver a sensação que está inclinando para a esquerda ...”, pois nós não temos acesso direto a qualquer fato externo. O sistema automático de processamento regido por nossas normas epistêmicas deve acessar informações sem primeiro termos que fazer julgamentos sobre esta informação: "Nós precisamos ter acesso não-epistêmico" (Pollock 1986, p.133). A utilização de normas confiabilistas ou probabilísticas demandaria a posse e o uso de outras crenças prévias - a respeito da confiabilidade de algum processo ou a probabilidade de algum fato - e isto anula a possibilidade que as normas que guiam nosso raciocínio sejam externalistas de alguma forma. ${ }^{2}$

Ao contrário do externalismo de crenças, o externalismo de normas admite que normas sejam internas na maneira descrita por Pollock. Esta posição, no entanto, se opõe ao internalismo ao defender que normas epistêmicas devem ser avaliadas externamente. Por exemplo, "pode ser alegado que um conjunto de normas inter- 
nalistas é melhor do que outro se o primeiro é mais confiável em produzir crenças verdadeiras" (1986, p.138). Pollock admite uma boa motivação para o externalismo de normas. De fato, normas regulativas geralmente não são imunes à apreciação. Normas regulativas para a ação, por exemplo, normalmente nos dizem como fazer algo através de outros atos. Assim, andar de bicicleta é uma ação não-básica que requer a realização de outras ações mais básicas como movimentos de braços, de pernas, etc., que podem ser realizadas de maneiras muito diferentes uma das outras. Uma avaliação externalista de ações não-básicas pode servir para mostrar qual a maneira mais eficiente de realizar uma ação, o que significa que algumas normas reguladoras são melhores do outras.

Embora à primeira vista pareça plausível, o externalismo regulativo de norma também é rejeitado. Segundo Pollock, esta posição é mantida apenas por uma concepção errônea fundamental - uma concepção que justamente visa ser corrigida pela tese central de sua teoria procedimental. A ideia, basicamente, é que considerações ou descobertas sobre confiabilidade podem sim alterar aspectos de nosso raciocínio, como o acréscimo ou eliminação de certos tipos de inferência, porém, isto não significa nenhuma mudança em nossas normas epistêmicas. Normas epistêmicas internalistas que governam nosso raciocínio "já acomodam criticismo baseado em confiabilidade" (1986, p.140). Para entendermos mais claramente o que Pollock quer dizer com isto, além da concepção naturalista em que ele está se baseando, é útil apresentar o que ele chama de Projeto Oscar. Pollock propõe que nos coloquemos na posição de um engenheiro que pretende construir uma máquina inteligente chamada Oscar. Oscar deve interagir com seu ambiente, aprender a partir da experiência e sobreviver em um ambiente razoavelmente complexo e hostil. A questão é: "o que nós deveríamos colocar em Oscar para fazê-lo funcionar?".

A descrição de Pollock sobre o aprimoramento desta máquina cognitiva pode ser resumida da seguinte forma. Em primeiro lugar, como parte de seu aparato orgânico básico, Oscar possuiria (1) sensores perceptuais projetados para detectar aspectos do mundo externo - sensores de dor, visuais, olfativos, táteis, auditivos, etc. — que forneceriam como outputs estados internos operáveis pelo sistema, (2) uma estrutura conativa para prover metas e motivações como "sempre evitar a dor" e "buscar alimento", (3) uma espécie de linguagem do pensamento, um sistema de representações mentais que permitisse a formação de pensamentos, proposições, crenças e a individuação de objetos, (4) certas normas epistêmicas que determinam ou geram a disposição que dado certos inputs sensíveis Oscar forme certas crenças, e (5) certas regras práticas que determinam que dado certas crenças, Oscar se comporte de algumas maneiras específicas. Obviamente, os pensamentos e crenças formados poresse sistema devem estar em uma relação adequada ao ambiente. Ou seja, este sistema deve funcionar de maneira que seus sensores perceptuais e regras epistêmicas produzam crenças que causem Oscar a ter um comportamento favorável à sua sobrevivência. 
Este aparato básico é o que o permite reagir ao ambiente e ter a mínima capacidade de permanecer vivo nele. No entanto, em um ambiente complexo as chances de uma máquina como esta seriam fatalmente baixas. A razão para isso é o fato de que pequenas alterações no ambiente poderiam ser suficientes para que o comportamento a que está programado se tornasse desfavorável para o mantimento de sua vida. Por exemplo, uma máquina programada somente a se afastar um pouco quando seus sensores de dor fossem ativados estaria com problemas se subitamente uma grande quantidade dos organismos que causam seus sensores de dor dispararem migrassem para o seu nicho. Apenas se afastar de um dos organismos não seria suficiente para que ele não fosse morto. Para aprimorar esta máquina poderíamos instalar sensores de segunda ordem que permitam que Oscar sinta quando está em dor, e adicionar novas normas epistêmicas que o torne hábil a fazer generalizações sobre que tipos de situações causam este tipo de situação e aprender como evitá-las.

As novas regras epistêmicas e sensores de segunda ordem devem funcionar de tal forma que permitam que Oscar possua uma forma de self-awareness. Oscar não deve apenar agir automaticamente ao sentir a ativação de seus sensores perceptuais ou a detecção de uma situação que possa ativar os sensores de dor, mas ser capaz, com o acúmulo de informações, de atentar para o funcionamento de seus próprios sensores, aprimorar a percepção dos fatores de seu ambiente e adequar seu comportamento. É este tipo de capacidade de adaptação que realmente torna Oscar bem sucedido e digno de ser chamado de uma máquina inteligente.

Assim, o que Pollock entende por normas epistêmicas são as regras que governam a aquisição e as operações de crenças do sistema de máquinas como Oscar. É claro, a ideia é que nós somos máquinas como Oscar e que nós possuímos regras que governam nossa aquisição e uso cognitivo de crenças, ipso facto existem normas epistêmicas como foram descritas. Isto torna mais claro a razão de Pollock rejeitar o externalismo de norma. Se constatarmos via acréscimo de informação que uma crença $p$ resulta de um processo confiável, e.g., de uma nova generalização, isto implica, segundo Pollock, em uma nova permissão para o sistema, mas não em uma nova norma epistêmica.

\section{Confiabilismo de Processo e Cognição Racional}

A teoria procedimental é naturalisticamente robusta. Há muito sentido em entender normas epistêmicas como as regras que já determinam a maneira com que raciocinamos. Ela responde à questão "o que é justificação epistêmica?" de um modo bastante direto e que estabelece laços muitos firmes entre a psicologia e a epistemologia. As regras responsáveis pelo status epistêmico de nossas crenças não são algo estranho às regras que são de fato usadas em um processo natural, biológico, fisiológico. Neste 
caso, o trabalho do epistemólogo é analisar as normas que constituem um fenômeno natural — algo a que Pollock dedicou grande parte de sua pesquisa. "Normas devem ser elucidadas a partir do que fazemos realmente e não a partir de algum critério misterioso, separado de nosso comportamento atual, que nos diz o que nós deveríamos fazer" (Pollock 1986, p.170). Com isso, prova que uma abordagem naturalista não é algo exclusivo a teorias externalistas. Algo que ainda não está claro, no entanto, é se este projeto naturalista realmente implica na refutação de qualquer forma de teoria naturalista externalista de justificação. Nesta seção, nós vamos analisar se a refutação de Pollock (1986) realmente atinge uma forma particular de externalismo, i.e., o confiabilismo de processo. Para isso, nós também vamos discutir os argumentos de Pollock e Joseph Cruz (2004).

É duvidoso se a refutação do externalismo Pollock (1986) funcione. Particularmente, ela não parece atingir uma forma específica de externalismo, viz., o confiabilismo de processo na maneira em que é proposto por Goldman $(1979,1986)$. Para tentar satisfazer os critérios substantivos que ele mesmo propõe (1979), Goldman (1986) primeiramente adota o que chama de "estrutura de regras" (rules framework - - uma estrutura neutra que permite diferentes concepções de justificação serem formuladas. Assim, um conjunto de regras-J, como as chama, deve especificar as maneiras em que uma crença pode ser formada, mantida ou atualizada para que ela possua justificação epistêmica. Embora isto possa soar como uma teoria procedimental, o tipo de regra que compõe o conjunto de regras-J de Goldman não é realmente regulativo, e isto é significativo contra a crítica de Pollock acima.

Goldman certamente assume a existência de normas regulativas da maneira que são entendidas por Pollock (1986). No entanto, em sua abordagem o que determina o status epistêmico de uma crença é uma avaliação que não pretende realmente ter força de regulação: "De fato, quando se trata de processos psicológicos fixados ou automáticos, não há sentido em oferecer princípios de orientação. No entanto, tais processos podem ser objeto de avaliação epistêmica" (1986, p.26). Em suas próprias palavras, a teoria que propõe é de uma "variedade não-regulativa" (1986, p.26, grifo nosso). O que a torna não-regulativa é o fato de que nela o status epistêmico de uma crença depende da satisfação de certas regras epistêmicas (o conjunto de regras$\mathrm{J}$ ), em lugar da instanciação de normas regulativas. Uma vez que a avaliação que esta teoria faz sobre nossos processos cognitivos é de um tipo não-regulativo, não há conflito real com a teoria de Pollock (1986), que afirma a impossibilidade uma teoria de natureza regulativa ser externalista. Se este é o caso, a sua rejeição ao externalismo falha.

Posteriormente, todavia, Pollock \& Cruz (2004) apresentam novos argumentos para a rejeição do externalismo e a adoção da teoria procedimental de normas que podem afetar versões não-regulativas do confiabilismo. $\mathrm{O}$ argumento central, desta vez, é uma crítica à relação entre justificação e crença verdadeira construída pelo

Principia 17(1): 19-38 (2013). 
confiabilismo de uma forma geral. Basicamente, Pollock \& Cruz (2004) acusam os externalistas de repetidamente estarem cometendo um mesmo erro, viz., o de perigosamente estarem "fundindo crenças racionais a crenças verdadeiras" (p.135, grifo nosso). É confuso afirmar, no entanto, em que exatamente se baseia esta acusação. Em boa parte de seu ataque, nós sugerimos, Pollock \& Cruz (2004) parecem simplesmente discordar fundamentalmente sobre qual objeto de análise é adequado para uma análise da justificação epistêmica. Para ilustramos isto, considere novamente a abordagem confiabilista de Goldman. Como foi colocado acima, uma estrutura de regras-J é neutra quanto a que concepção de justificação deve ser formulada. Mas diferentes teorias podem ter concepções diferentes sobre que tipos de processos e relações permitem que uma crença seja justificada e, portanto, apresentar conjuntos de regras-J incompatíveis entre si. Uma questão que obviamente surge é: como decidir entre conjuntos de regras-J diversas?

Para responder a isto, Goldman (1986) defende uma abordagem consequencialista para determinar o critério correto para o conjunto de regras-J, e avalia uma série de possíveis abordagens consequencialistas. Dentre possíveis consequências valoráveis, ele lista consequências "veritativas" (verific) e uma série de consequências não-veritativas, como consequências explanatórias e coerentistas. Goldman então argumenta que grupos de regras que favorecem consequências não-veritativas falham em classificar como justificadas um corpo de crença que intuitivamente não consideramos justificadas. Teorias de regras com consequências explanatórias e coerentistas, por exemplo, podem ser satisfeitas por sistemas de crenças geradas por paranóia, mecanismos neuróticos ou pura fantasia. "[S]e essas construções fantasiosas forem consistentemente falsas, eu me sentiria muito pouco inclinado a dizer que este tipo de processo confere justificação. Certamente ele não produz o tipo de justificação que nos aproxima de 'conhecimento' " (1986, p.101). A conclusão é que o critério correto para a teoria de justificação é um critério ligado à verdade (truth-linked). Mais especificamente, um critério confiabilista de mera maximização de crenças verdadeiras não parece adequado, pois há algo de anti-intuitivo nas consequências de um conjunto de regras-J que não imponha nenhuma restrição sobre o número de crenças falsas - um conjunto de crenças com crenças verdadeiras, mas também com um grande número de crenças falsas não parece ser uma consequência que valorizamos. Podemos, assim, resumir o seguinte critério:

Critério confiabilista geral: um conjunto ou sistema de regras-J é adequado se e somente se permite processos cognitivos cuja instanciação resulta em um conjunto de crenças com uma relação de crenças verdadeiras (em relação a falsas) intuitivamente alta o bastante. ${ }^{3}$

Pollock \& Cruz (2004) criticam a ideia de utilizar a verdade como um standard para avaliar epistemicamente a produção de crenças: "Nós pensamos que Goldman 
está fundamentalmente confuso neste ponto [...] não ser verdadeira não é de nenhuma forma uma crítica à uma crença que é justificada de outra maneira" (p.133). Grosso modo, tomar a verdade como o valor crítico de crenças seria enganoso porque tanto um conjunto de crenças quanto o token de uma crença podem possuir justificação mesmo que falsos:

O tipo de julgamentos que nós faríamos sobre nossa realização intelectual se nós insistirmos que crenças justificadas devem ser crenças verdadeiras em sua maioria seria completamente bizarro. Nós acabaríamos insistindo que a maioria do que foi acreditado sobre o mundo natural nos últimos 6000 anos foi não somente falso, mas também irracional [...] Isto parece completamente errado. (Pollock \& Cruz 2004, p.133)

Este argumento específico é prima facie pouco convincente uma vez que um confiabilista de processo obviamente não iguala crença justificada à crença verdadeira. Mais significativo, entretanto, é que Pollock \& Cruz parecem sugerir que o confiabilismo escolhe o objeto de análise inadequado ao adotar um standard de avaliação diretamente ligado à verdade. No trecho acima, assim como em muitos momentos, Pollock \& Cruz (2004) estão acusando os externalistas de estarem defendendo um critério errado para a avaliação de crenças racionais: "Goldman está afirmando que crenças racionais têm alguma coisa em comum e que esta coisa em comum, confiabilidade, é constitutiva de crenças justificadas" (p.130, grifo nosso). Em outro ponto, eles atribuem a origem da contínua atração do externalismo de justificação à "perspectiva específica sobre a convicção de que a verdade é o standard avaliativo único ou primário no qual a racionalidade é julgada" (p.125, grifo nosso).

Existe bastante sentido em afirmar que justificação não precisa estar conectada à crença verdadeira da maneira defendida, por exemplo, por confiabilistas se constatamos que a racionalidade não está. Para fornecermos uma explicação informativa sobre por que a nossa cognição funciona do jeito que funciona, nós precisamos obrigatoriamente olhar para as pressões da engenharia evolutiva que definiram nossa arquitetura cognitiva, e aqui a verdade possui um papel bem mais coadjuvante. Em primeiro lugar, as regras que realmente regem a formação de crenças em nosso sistema cognitivo têm como objetivo proximal o que é exigido pelas próprias normas epistêmicas do sistema, i.e., o processamento de certos estados e informações internos de tal e tal maneira, e isto anula a possibilidade da verdade fazer parte da formulação destas normas - isto consiste justamente na refutação do confiabilismo de crença. Em lugar disto, nossas normas epistêmicas em grande escala parecem ter sido projetadas para gerar "raciocínio anulável" (defeasible reasoning), ou seja, normas que intrinsecamente autorizam à possibilidade de produção ou conservação de falsidades. Este é um ponto constantemente reforçado por Pollock ao longo de sua obra:

Principia 17(1): 19-38 (2013). 


\begin{abstract}
Um agente sofisticado deve ser capaz de descobrir generalizações sobre seu ambiente raciocinando indutivamente, mas raciocínio indutivo é anulável — nova evidência pode derrubar generalizações anteriores. Porque percepção permite somente que um agente monitore pequenas partes de seu ambiente por vez, a fim de construir um modelo de mundo coerente, o agente deve combinar conclusões desenvolvidas com base em diferentes experiências perceptuais ocorrendo em tempos diferentes. Mas isto requer a suposição anulável de que o mundo não muda tão rapidamente, tal que o que foi percebido a pouco tempo ainda é verdadeiro (2001, p.2).
\end{abstract}

Outro ponto é o de que da perspectiva de uma teoria da racionalidade, cognição epistêmica e cognição prática "são avaliados em pacote" (p.140). O critério confiabilista não faz sentido porque o objetivo último da racionalidade não é a produção de um grande número de crenças verdadeiras, "mas o sucesso prático através da operação de normas epistêmicas" (p.140). ${ }^{4}$ Uma vez que a definição de crença racional obrigatoriamente apela para as normas que nós de fato utilizamos na formação de crenças, não é possível avaliar a racionalidade de crenças externalisticamente. De fato, é possível, em princípio, gerar um grande conjunto de crenças falsas onde todas elas sejam racionais. É necessário apenas que elas tenham sido geradas por nossas normas epistêmicas, i.e., que o sistema cognitivo tenha feito tudo que estava epistemicamente ao seu alcance. ${ }^{5}$ Assim, mesmo uma teoria confiabilista não-regulativa falha ao estabelecer um standard confiabilista maximal, pois esta avaliação não faz sentido de um ponto de vista naturalista.

Embora este argumento seja válido, há, entretanto, um problema sério e bastante óbvio na insistência de Pollock em atacar o standard avaliativo do confiabilismo a partir de uma teoria naturalista da racionalidade: este não é o objeto de análise tratado pelo confiabilismo de processo. Pollock claramente entende justificação epistêmica como idêntica ao conceito de cognição racional, mas nada do que os aspectos factuais de uma teoria da racionalidade impliquem podem afetar uma teoria cujo projeto é naturalizar um conceito diferente. Sua crítica realmente não faz jus ao rationale do confiabilismo de processo e é algo a que Goldman (1986), por exemplo, pode responder imediatamente ao afirmar que racionalidade "é uma desiderato epistêmico amplamente citado, um que é possível para os seres humanos mesmo que ambos, conhecimento e justificação, não sejam. Pode ser possível ter crenças racionais mesmo que o conhecimento seja inexequível" (Goldman 1986, p.40). Podemos explicitar as diferenças entre o conceito de cognição racional capturado pela teoria procedimental de normas e o conceito de justificação epistêmica que um confiabilista de processo pretende capturar através de uma analogia com relação ao projeto Oscar.

Imagine que realmente tenhamos sido bem sucedidos em construir Oscar, uma máquina pensante idêntica a nós. Ele possui exatamente as mesmas regras que re- 
gem nosso raciocínio, tanto prático quanto epistêmico, e sensores externos tão apurados quanto os nossos. A pergunta primária para um projeto naturalista de justificação epistêmica é: Qual é a base factual em Oscar de onde sobrevêm a justificação de suas crenças? O confiabilista de processo e Pollock respondem diferentemente a esta questão. Para Pollock, como já ficou claro, a justificação epistêmica equivale à conformidade das crenças de Oscar com as regras epistêmicas que regem seu raciocínio. Uma consequência é a de que se Oscar for introduzido ao nosso mundo como supomos que ele é - qualquer que seja a crença adquirida por Oscar seguindo suas normas epistêmicas serão justificadas, mesmo uma crença falsa que viria a ser anulada com o acúmulo de informação. Isto não corresponde à noção de justificação que o confiabilismo de processo quer capturar. O conceito de justificação visado pelo confiabilista possui uma relação explícita com o conceito de conhecimento. $\mathrm{O}$ confiabilista está interessado na base factual que permite Oscar adquirir crenças verdadeiras sobre o mundo externo, i.e., formar conhecimento, para poder determinar o que precisa ser verdade sobre as bases de uma crença para que ela seja justificada.

Uma diferença fundamental entre as concepções de justificação de Pollock e do confiabilismo de processo diz respeito à importância dada à gênese empírica que pode estar envolvida na aquisição de crenças. Se estamos tratando de cognição racional, qualquer crença permitida pelo conjunto de normas epistêmicas é justificada. Quando estamos lidando com o que gera conhecimento em Oscar, entretanto, experiência empírica possui um papel muito importante, e muitas crenças autorizadas pelo sistema cognitivo não são justificadas. Alguns processos cognitivos que realizamos são essencialmente não-inferenciais. Por exemplo, se Oscar é idêntico a nós, ele possui, uma capacidade inata e muito confiável de reidentificar um objeto a como sendo o objeto $a$, o que permite que Oscar indutivamente acumule informação sobre $a$. Assim, Oscar possui um mecanismo de identificação que o permite estar certo sobre muitas proposições envolvendo a identificação de objetos. O mesmo vale para outras capacidades perceptuais.

Todavia, é impossível que Oscar adquira conhecimento sobre inúmeros outros fatos se foi inserido há pouco tempo no mundo, por mais bem projetado que ele assim como nós - seja. Muitos fatos só são conhecidos se, por exemplo, tivermos experiências o suficiente para fazermos generalizações corretas. Nossas inferências são regidas por nossas normas epistêmicas, mas um processo inferencial token só pode gerar conhecimento do mundo externo se as generalizações e informações que está utilizando são verdadeiras. ${ }^{6}$ Em outras palavras, a capacidade de aquisição de conhecimento de um indivíduo é enormemente influenciada pela experiência que este indivíduo adquire.

A resposta do confiabilista sobre quais são as bases factuais da justificação, portanto, é em termos de processos geradores de conhecimento. Para determinar as condições para que uma crença seja justificada uma teoria deste tipo deve identificar 
que tipos de processos tipicamente geram conhecimento, i.e., são confiáveis, e experiência e aprendizado possuem um papel essencial neste ponto. ${ }^{7}$ Nada do que vimos até agora no ataque de Pollock (1986; Pollock \& Cruz 2004) ao externalismo fornece realmente argumentos consistentes contra este projeto. Com vamos ver, entretanto, ele também possui razões para criticar este projeto em si. Na seção seguinte nós vamos analisar que razões Pollock pode realmente utilizar contra o confiabilismo de processo.

\section{Qual o Problema com o Confiabilismo de Processo?}

Pollock não está meramente confuso sobre em que consiste realmente o projeto naturalista do confiabilismo de processo. Na verdade, ele parece apenas possuir um forte pessimismo sobre a realização deste projeto, e se ocupa ao longo de toda sua análise em já introduzir sua proposta de adotarmos o projeto de naturalização do conceito de cognição racional. Existem duas razões aparentes para o pessimismo de Pollock \& Cruz (2004). Em primeiro lugar, eles afirmam que a motivação em utilizar o standard confiabilista baseado em um conceito de conhecimento é errônea. Epistemólogos têm se ocupado há um longo tempo com a análise do conhecimento e a utilidade de relacionar este projeto ao desenvolvimento de uma teoria da justificação é questionável. Por exemplo, se alguém está interessado em solucionar o problema de Gettier (1963) para o conhecimento, pode fundir este interesse a uma análise da justificação, e não está claro qual é a relação exata entre a justificação e a natureza dos contraexemplos de Gettier. Solucionar este problema via uma teoria da justificação requer forjar uma conexão muito forte entre a verdade e os fatores de justificação.

Esta ideia, todavia, não é convincente. É perfeitamente possível para o confiabilismo de processo separar uma teoria da justificação dos problemas relacionados à análise do conhecimento. É útil enfatizar que uma instância de um processo confiável não implica em um caso de conhecimento. Uma crença gerada por um processo confiável pode tanto ser falsa como verdadeira sem constituir um caso de conhecimento, pois a análise do conhecimento pode revelar a existência de outros critérios de satisfação para conhecimento. É possível, por exemplo, defender que o estado de conhecimento requer a existência de certos estados externos favoráveis, mas demandar estas especificações apenas para uma teoria do conhecimento posterior, enquanto nos ocupamos em especificar que processos são confiáveis.

Embora seja um ponto a que pouco dão atenção, a segunda razão que Pollock \& Cruz (2004) apontam para o pessimismo quanto ao projeto confiabilista levanta um problema bem mais sério. O motivo da pouca atenção não é por subestimarem sua importância, mas por se tratar de um problema já bem conhecido à literatura 
epistemológica, viz., o problema da generalidade. A teoria confiabilista deve detectar os processos que possuem em comum a propriedade da confiabilidade. É uma consequência, portanto, que estes sejam processos tipos (types), pois somente processos tipos são entidades repetíveis que podem produzir crenças verdadeiras ou falsas. Grosso modo, o problema da generalidade é um problema de tipificação. Um processo causal token de uma crença pode ser tipificado de inúmeras formas, menos ou mais amplas. O problema é que dependendo da forma em que um processo é tipificado, o índice de confiabilidade deste processo muda, e não parece haver uma resposta óbvia sobre qual o modo correto de selecionar um processo para assinalar sua confiabilidade.

Tomemos um processo visual como exemplo. Digamos que Jean está preocupado com o paradeiro de seu gato de estimação, Tiggy, quando olha pela janela e vê seu gato dormindo no jardim de sua casa, e então forma a crença $p$ : "meu gato está no meu jardim". Como devemos individuar o processo envolvido na produção de $p$ neste caso? O tipo relevante seria simplesmente causação perceptual, deve incluir os processos de categorização de GATO de Jean, os processos de categorização de TIGGY de Jean, ou detalhes causais da estimulação na retina de Jean particulares a esta instância? Cada uma destas individuações possui um índice de confiabilidade diferente, sendo até mesmo possível que uma descrição muito estreita leve a um índice de confiabilidade absoluta. Além disto, pode-se questionar se fatores do ambiente devem ser considerados para medir a confiabilidade do processo. Devemos incluir na individuação do processo a luminosidade do jardim de Jean, ou a opacidade de sua janela? Questões deste tipo têm sido colocadas desde o início do projeto confiabilista e sua dificuldade foi notoriamente reconhecida por Goldman (1986). O que é particularmente importante para nós aqui é o fato de que este é um problema que realmente diz respeito ao projeto naturalista do confiabilismo de processo. Confiabilistas devem uma solução para o problema da tipificação caso queiram que a possibilidade de uma teoria confiabilista de processo ser desenvolvida seja levada a sério. Este, ao menos à primeira vista, é um ponto que realmente justifica o pessimismo de Pollock \& Cruz (2004) quanto ao confiabilismo de processo per se. É possível responder a esta objeção?

\section{Mantendo o Projeto Confiabilista}

Dado todo o ataque de Pollock ao externalismo, o principal argumento que ele pode colocar especificamente contra o confiabilismo de processo - embora ele não o coloque de fato - é algo como: "vamos abandonar a tentativa de tipificar processos que não parecem ser realmente tipificáveis e apenas elucidar os padrões de raciocínio que realmente utilizamos". Nesta última seção, nós vamos defender o confiabilismo 
contra esta sugestão substitutiva. Embora o confiabilismo de processo pareça sofrer com um problema sério, nós defendemos que este problema não coloca realmente o projeto da teoria procedimental de normas em vantagem. O problema da generalidade é um ponto que já foi extensamente discutido na literatura e, portanto, a resposta que vamos utilizar não é nova. Nós não pretendemos entrar em detalhes desta discussão, mas apenas adaptar um contra-argumento baseado na resposta que Juan Comesaña (2006) propõe ao problema. Para isso, no entanto, devemos introduzir brevemente alguns pontos desta discussão.

A resposta primária comum de um naturalista ao problema da generalidade é a de que o tipo de processo relevante a ser selecionado é um tipo científico, i.e., uma resposta deve identificar os processos adequados em termos científicos - processos que possam ser tipificados por uma ciência cognitiva. Uma resposta deste tipo é proposta por William Alston (1995). Baseado na própria definição de processo de Goldman (1986), Alston defende que "cada formação de crença envolve a ativação de certa função psicológica realizada (...) A função envolvida irá determinar tanto que aspectos do input têm influência sobre a crença de saída e que influência eles têm" (1995, p.17). Em outras palavras, a ideia de Alston é que existe um tipo psicológico natural em cada processo de formação de crença, um esquema funcional da forma "a partir de tais e tais inputs mentais - proposicionais ou não — produzir tal e tal saída doxástica" a ser preenchido pela função realmente operativa em cada processo de formação de crença. A função psicológica selecionada é o tipo relevante de processo no qual a confiabilidade deve ser avaliada. A posição de Alston (1995), portanto, é uma espécie de realismo psicológico, i.e., a posição de que existem tipos naturais psicológicos que constituem tipos de processos.

Earl Conee e Richard Feldman (1998), os principais autores a criticarem o confiabilismo de processo devido ao problema da generalidade, admitem que uma resposta em termos de funções psicológicas diminui o número de processos relevantes que podem ser tipificados. Entretanto, afirmam que esta restrição não é suficiente para solucionar o problema, pois o token de uma função ainda instancia inúmeros tipos de processos distintos. Para ilustrar seu ponto, Earl \& Conee (1998) debatem o caso em que Smith se depara com uma macieira e forma a crença "esta árvore é uma macieira". Muitos processos podem ser tipificados a partir de um input sensorial da macieira e a crença resultante. Existe uma função mais estreita que vai do formato das folhas das árvores para a crença particular de que há uma macieira por perto. Uma outra função que mapeia uma variedade de inputs visuais semelhantes, que inclui o formato de folha particular que Smith percebe, e leva ou à crença de que há uma macieira por perto, ou a crença de que há um carvalho por perto, ou à crença de que há um olmo por perto. Outra função mais ampla pode incluir além do par funcional 〈input visual, macieira〉, uma série de outros inputs sensoriais, etc. Entre outras. Conee \& Feldman concluem que "o evento da formação da crença manifesta 
todas elas. Então, neste e em outros casos típicos, existe uma infinidade de tipos psicológicos realmente operativos" (1998, p.12, grifo nosso).

Posteriormente, Jonathan Adler e Michael Levin (2002) defenderam a resposta de Alston ao problema. Adler \& Levin (2002), basicamente, argumentaram que Conee \& Feldman não estão descrevendo funções ao discutir o caso de Smith, mas a mesma função em níveis diferentes de detalhe. Este argumento também foi seguido por uma tentativa de resposta de Conee \& Feldman (2002). O que mais nos interessa neste debate, no entanto, é a colaboração recentemente feita por Comesaña (2006). Ao invés de tentar simplesmente fornecer uma nova resposta ao problema da generalidade, Comesaña importantemente argumenta que este não é um problema especial do confiabilismo, mas parece atingir qualquer teoria adequada de justificação.

Por exemplo, Conee \& Feldman (1985) defendem a teoria geral conhecida como evidencialismo, que diz essencialmente que uma crença $p$ de $S$ é justificada se e somente se ela se encaixa (fits) com a evidência de $S$. Obviamente, " $p$ se encaixar à evidência de $S$ " é algo vago demais para constituir uma teoria. Em uma caracterização um pouco mais específica, Conee \& Feldman (1985) defendem que para ser justificada, uma crença não deve apenas se encaixar à evidência de $S$, mas ser baseada em seu corpo de evidência. Isto impede, por exemplo, que a crença de que "tem um ladrão dentro da minha casa" seja justificada quando é gerada por um trauma emocional ao invés da evidência que $S$ realmente possui para acreditar que há um ladrão em sua casa. O problema, entretanto, é que uma teoria que utiliza a noção causal de "ser baseado em" parece encontrar exatamente as mesmas dificuldades de tipificação que uma teoria confiabilista. Esta noção foi invocada justamente para dar conta de situações em que crenças não são geradas ou mantidas pelas relações causais visadas pela teoria evidencialista, como situações em que $p$ realmente se encaixa à evidência de $S$ mas é sustentada por relações causais desviantes, e.g., "medos irracionais", "wishful thinking", etc. Isto, no entanto, é idêntico a dizer que algumas crenças são causadas por fatores psicológicos adequados e outras não, i.e., que existem tipos de relações causais adequados e tipos inadequados. Evidencialistas, portanto, nos devem uma teoria de tipificação tanto quanto os confiabilistas, e enfrentam as mesmas dificuldades de tipificação relacionadas ao problema da generalidade.

O ponto de Comesaña (2006) não é o de que o evidencialismo também sofre com o problema, mas o de que um problema muito similar vale para qualquer teoria de justificação adequada. Uma vez que toda teoria de justificação deve se preocupar com os tipos de contraexemplos que podem ser utilizados contra a forma geral do evidencialismo, e deve restringir sua proposta de definição a uma relação causal adequada entre a crença e os antecedentes mentais de $S$, ou entre a crença e o ambiente, etc., todas parecem utilizar uma concepção semelhante à "ser baseado" e, portanto, estarem sujeitas a um problema de tipificação. Para o interesse deste artigo, nós sequer precisamos discutir se a generalidade do ponto de Comesaña é 
válida ou não. Nosso interesse aqui diz respeito à teoria procedimental de normas. Nós podemos agora rejeitar sua proposta substitutiva.

O mesmo ponto que Comesaña coloca sobre o evidencialismo - e talvez sobre qualquer teoria de justificação - também se aplica à teoria procedimental de normas. A definição de quando uma crença é racional ou justificada é dada pela teoria procedimental, porém apenas de uma forma vaga. O projeto de Pollock, assim como o de Goldman (1986), é um projeto que para ser completado ainda deve ser adequadamente desenvolvido com uma boa dose de ajuda das ciências cognitivas. Pollock, particularmente, além de elucidar quais são de fato nossas normas regulativas, ainda nos deve uma teoria detalhada sobre quando uma crença é gerada em conformidade com estas normas e quando elas não são. Digamos que nós abandonamos a tentativa de desenvolver uma teoria de justificação e assumimos o projeto de desenvolver uma teoria da cognição. Uma teoria substantiva da cognição racional deve especificar todas as condições factuais que tornam uma crença racional. Tomemos novamente o caso de Smith como exemplo. Smith se depara com uma macieira e forma a crença "esta árvore é uma macieira". Esta crença é racional? A resposta a essa questão é muito mais difícil do que é evidenciado por Pollock. A relação causal relevante entre normas epistêmicas e a crença - a relação factual que significa "em conformidade com" - é apenas a relação causal envolvida na instanciação das normas deste processo token? Se sim, isto é problemático porque existem formas mais amplas e mais estreitas de se caracterizar um único processo. É uma relação que inclui a influência das normas epistêmicas ao longo de toda a aquisição de informações que resultaram na atual capacidade de categorização de Smith? Neste caso, quanta influência é suficiente para a formação de crença racional? Todos os processos tokens envolvidos na aquisição de informações agora utilizadas neste processo devem ter sido guiados por normas epistêmicas? Se não, que proporção de processos deve ter sido?

Outra complexidade da teoria da cognição racional que implica em problemas de tipificação diz respeito à relação entre racionalidade e irracionalidade. Pollock $(1986,2007)$ atribui a possibilidade de irracionalidade do ser humano à existência de mecanismos heurísticos em nosso sistema cognitivo - mecanismos selecionados evolutivamente por terem sido úteis em ambientes passados, mas que muitas vezes possuem resultados inadequados nos ambientes atuais. Segundo Pollock (2007), toda irracionalidade pode ser atribuída à existência destes mecanismos. Mas isto não livra sua teoria de problemas de tipificação ou vaguidades. Uma crença pode ser irracional, porque é possível desviar de formas de raciocínio padrão — devido aos mecanismos heurísticos. Mas que tipos de raciocino são formas padrão? Pollock provavelmente tem que recorrer a algumas listas de esquemas para responder a esta questão, mas, como já vimos, existem formas mais amplas e mais estreitas de tipificar um processo padrão. Além disto, uma vez que a racionalidade epistêmica e a racionalidade prática são julgadas em pacote (Pollock \& Cruz 2004), pode ser 
muito difícil determinar quando uma crença é mantida por relações causais que podem ser consideradas racionais ou não. Por exemplo, algumas formas de cognição são infectadas por desejos ou estados emocionais do indivíduo, e afetam inclusive os processos de acesso à memória (Stipek 1984). Algumas influências conativas ou emocionais podem fazer com que o indivíduo não se empenhe em certos processos padrões, como revisar a evidência que possui relacionada a esses estados mentais. Quando é racional manter um estado doxástico afetado por estas influências? Pollock não tem como responder a isto sem apelar para que tipos de influências causais são adequadas, e quais são inadequadas.

A última resposta que podemos dar ao ataque de Pollock ao externalismo, portanto, é a de que os detalhes de seu projeto também incluem problemas de tipificação. Se há ou não uma maneira óbvia de uma teoria que assume o realismo psicológico resolver problemas deste tipo, isto afeta tanto o confiabilismo de processo quanto outras teorias naturalistas que apelam para o funcionamento de nosso sistema cognitivo. Desta perspectiva, então, não há realmente uma vantagem teórica para a qual Pollock possa apelar contra o confiabilismo de processo.

\section{Conclusão}

Nós discutimos a suposta refutação de Pollock ao externalismo através de uma abordagem naturalista. Sugerimos que a proposta de Pollock é essencialmente a de substituir o projeto de naturalização da justificação epistêmica pelo projeto de naturalização da cognição racional, e mostramos então a diferença entre este projeto e o da teoria naturalista mais corrente do externalismo, i.e., o confiabilismo de processo. Avaliamos quais razões Pollock pode realmente utilizar contra este projeto e concluímos que a principal delas seria o conhecido problema da generalização para o confiabilismo. Utilizamos então uma resposta recente de Comesaña (2006) para argumentar que este problema não fornece vantagem para o projeto de Pollock, mas, ao contrário, também o afeta. Isto, no mínimo, faz com que ambos os projetos estejam no mesmo patamar, e leva à falha de sua proposta substitutiva.

\section{References}

Adler, J.; Levin, M. 2002. Is the Generality Problem too General? Philosophy and phenomenological Research LXV(1): 87-97.

Alston, W. 1995. How to Think About Reliability. Philosophical Topics 23: 1-29.

BonJour, L. 1980. Externalist Theories of Empirical Knowledge. Midwest Studies in Philosophy 5: 53-73.

Comesaña, J. 2006. A Well-Founded Solution to the Generality Problem. Philosophical Studies 129: $27-47$.

Principia 17(1): 19-38 (2013). 
Conee, E.; Feldman, R. 1998. The Generality Problem for Reliabilism. Philosophical Studies 89: 1-29.

- 2001. Internalism Defended. In: Kornblith 2002, p.231-60.

2002. Typing Problems. Philosophy and Phenomenological Research LXV(1): 98-105.

Gettier, E. 1963. Is Justified True Belief Knowledge? Analysis 23: 121-3.

Goldman, A. I. 1976. Discrimination and Perceptual Knowledge. In: Goldman 1992, p.85104.

- 1979. What is justified belief? In: Goldman 1992, p.105-26.

- 1986. Epistemology and Cognition. Cambridge, MA: Harvard University Press.

- 1992. Liaisons: Philosophy Meets the Cognitive and Social Sciences. Cambridge, MA: MIT Press.

Kornblith, H. 2002. Knowledge and its Place in Nature. Oxford University Press.

Pollock, J. 1986. Contemporary Theories of Knowledge. Totawa, NJ: Rowman and Littlefield.

-1990. Nomic Probability and the Foundations of Induction. Oxford University Press.

- 1995. Cognitive Carpentry. MIT Press.

- 1997. Reasoning about change and persistence: a solution to the frame problem. Nôus 31: 143-69.

- 2002. Defeasible reasoning with variable degrees of justification. Artificial Intelligence 133: 233-82.

- 2007. Irrationality and Cognition. In: Quentin Smith (ed.) Epistemology: New philosophical essays, New York: Oxford University Press.

Pollock, J.; Cruz, J. 2004. The Chimerical Appeal of Epistemic Externalism. In: R. Schantz (ed.) The Externalist Challenge. Berlin: De Gruyter, p.125-42.

Pollock, J.; Oved, I. 2006. Thinking about Acting: Logical Foundations for Rational Decision Making. New York, Oxford.

Stipek, D. J. 1984. Young Children's Performance Expectations: Logical Analyses or Wishful Thinking. In: I. Nicholls (ed.) Advances in Motivation and Achievement, vol. 3, Greenwich, Conn.: JAI Press.

ARTHur Viana Lopes

Programa de Pós Graduação em Filosofia Universidade Federal do Rio Grande do Sul arthurvlopes@gmail.com

Resumo. Neste artigo nós tratamos da crítica de John Pollock ao externalismo, a qual consiste na ideia de que uma teoria de justificação naturalista adequada deve ser internalista. Nós analisamos se sua refutação realmente atinge toda forma de externalismo e, em particular, o confiabilismo de processo. Nós apresentamos a teoria procedimental de normas epistêmicas de Pollock e discutimos se as razões que ele apresenta podem realmente refutar o confiabilismo de processo. Nós defendemos que as razões que são apresentadas não colocam realmente o projeto de Pollock em vantagem.

Palavras-chave: Externalismo epistêmico; naturalismo; confiabilismo; justificação.

Principia 17(1): 19-38 (2013). 


\section{Notas}

1 "Eu vou pensar em justificação epistêmica como dizendo respeito a questões da forma: quando é permissivo (de um ponto de vista epistemológico) acreditar em p?" (1986, p.132) ${ }^{2}$ Alguém poderia aqui objetar que apesar de julgamentos não serem realizáveis imediatamente, os resultados de julgamentos sobre confiabilidade podem ser processados pelas normas epistêmicas e, portanto, a norma confiabilista ainda seria automática. No entanto, esta objeção falha. De qualquer maneira, o tipo de norma que é defendida por confiabilistas jamais poderia ser o tipo de regra regulativa descrito por Pollock. O que o confiabilista propõe como critério não é que o processo cognitivo que é utilizado para gerar uma crença seja julgado confiável por seu próprio sistema, mas que ele seja realmente confiável, e esta condição por definição não é um estado interno.

${ }^{3}$ Nós não estamos reproduzindo literalmente o critério que Goldman (1986) formula, mas um critério confiabilista que pode ser defendido inspirado em seu trabalho.

${ }^{4}$ Nós duvidamos que seja possível tentar reduzir a avaliação da cognição epistêmica em termos de cognição prática sem recair em um critério confiabilista. Nós não vamos, entretanto, construir uma argumentação aqui porque isto se afasta de nosso tema central. Para um argumento deste tipo, ver (Kornblith 2002).

${ }^{5}$ Não estamos aqui obrigatoriamente imaginando um cenário radical como um em que existe um demônio maligno enganador, mas, por exemplo, um caso de extrema má sorte epistêmica.

${ }^{6}$ Até mesmo processos não-inferenciais podem requerer previamente informações empíricas para gerar conhecimento adequadamente. Processos de reidentificação, por exemplo, às vezes requerem certo número de encontro com os objetos. É por isto que, por ilustração, os processos de identificação de um ornitólogo experiente são bem mais confiáveis do que os de um amador.

${ }^{7}$ Nós estamos aqui propositadamente ignorando as complicações sobre em que devem se basear as medidas para a confiabilidade de processos, viz., que extensão de situações ou mundos possíveis um processo deve predominantemente produzir crenças verdadeiras para ser qualificado como confiável. Uma posição específica sobre este ponto é dispensável para o tema deste artigo. De qualquer forma, entretanto, podemos assumir nesta discussão a mesma posição de Alston (1995) de que a confiabilidade é medida em termos de produção de crenças verdadeiras no mundo atual - ao menos o que assumimos ser nosso mundo atual. Grosso modo, um processo é confiável se gera crenças verdadeiras diante de um grande número de situações que tipicamente encontramos, no ambiente em que vivemos.

Principia 17(1): 19-38 (2013). 